\title{
JUDICIAL DECISIONMAKING AND LITIGATION EXPENDITURE
}

\author{
AVERY KATZ \\ Law School and Department of Economics, University of Michigan, \\ Ann Arbor, MI, 48109, USA
}

\section{INTRODUCTION}

Recent years have borne witness to a striking increase in expenditures on legal services. ${ }^{1}$ Various critics of the U.S. legal system have accordingly argued that amounts currently spent on or in anticipation of disputes are socially excessive, and several writers have attempted to address the issue through economic analysis. - Much of the economic literature has centered on the choice between litigation and settlement, and most of the models cither assume a fixed exogenous level of litigation costs or treat such costs as the reduced-form outcome of litigants' maximization decisions. ${ }^{3}$

This article abstracts from the possibility of settlement to focus on the partics" behavior at trial. While much of the recent literature on litigation has emphasized suit and settlement, that research strategy is not the only useful one. Though most disputes do not rise to the level of a lawsuit and though the great majority of lawsuits end in settlement, decisions at earlier stages of a lawsuit depend on the parties" estimates of the ultimate consequences of litigation. Analysis of the litigation stage is therefore logically prior to any andysis of the decision to sue or of settlement negotiation. Furthermore, the relatively small but absolutely large number of cases that go to trial consume substantial resources in doing so, and many cases that settle do so only after substantial expenditure has been incurred in preparation for trial. ${ }^{4}$

Accordingly, I developed a model of litigation expenditure based on the assumption that the parties are already engaged in a dispute. Within the model, the outcome of litigation is a probability $q(X, Y)$ that the defendant will be found liable. with the probability increasing with the plaintiff's expenditure on legal resources and decreasing with defendant's expenditure. More specifically, the parties expend resources on legal research to produce arguments or favorable facts to a court or other decisionmaking body such as a jury or administrative agency. The court finds for the plaintiff if and only if a certain function of the parties' arguments, plus a random variable, exceed a liability threshold. The framework yields some interesting comparative statics predictions about the judicial process.

Section II of this article outlines the basic approach to modeling the litigants" expenditure decision and describes the model of judicial decisionmaking that is the focus of the analysis. Section III analyzes the behavior of maximizing litigants. Section IV analyzes the Nash equilibrium in expenditure and the determinants of

This paper is based on chapter I of the author's Ph.D. dissertation. I am grateful to Richard Caves, Sharon Feldman, Louis Kaplow, Joseph P. Kalt, Greg Mankiw. Andrew Lo, Suzanne Scotchmer, Steven Shavell, various seminar participants, and an anonymous referee for helpful comments. 
the probability of liability. Section $\mathrm{V}$ summarizes the main results and suggests possible extensions of the analysis.

\section{SUMMARY OF MODEL}

Suppose that two risk-neutral parties have a dispute over stakes with monetary equivalent $A$, and suppose that there is no consumptive value to litigation. The amount of the stakes $A$ is not in dispute in the lawsuit, which is solely over the liability issue. The plaintiff asks the court to award her $A$ dollars from the defendant. The court grants the award with probability $q(X, Y)$, where $q$ depends positively on plaintiff's expenditure $X$ and negatively on defendant's expenditure $Y$. The function $q($.$) and the specific values of X$ and $Y$ are known to both parties. I assume there is no agency problem between attorney and client, so that a party's legal expenditure is chosen to maximize her expected wealth after the litigation. The marginal cost to the plaintiff of legal services is $C$ dollars per unit, while the defendant's unit cost is normalized to $\$ 1$. The effect of changes in the defendant's marginal cost will be analyzed by appealing to symmetry. ${ }^{5}$

In this setting, a natural outcome for the litigation game is a Nash equilibrium in expenditure, where each party's expenditure is an optimal response taking her opponent's expenditure level as given. Of course, one can imagine plausible situations in which litigants might act preemptively, reasoning that the opponent will respond by altering her decision (e.g., a litigant might make an otherwise unnecessary discovery request because she expects that it will force her opponent to expend substantial resources in response). Nonetheless, there is substantial justification for adopting the Nash equilibrium approach. The strongest reason is that such preemptive action does not form a credible threat: were the opponent to react in the way the preempting party hoped, the preempting party would then find it in her interest to discontinue the preemptive action. A second justification for the Nash approach is that in many cases the litigants may not have information about their opponents' actual levels of expenditure, so that attempts at intimidation and provocation may fail due to an inability to communicate them to the opponent. The Nash equilibrium, in contrast, does not require any communication. Instead, each party can analyze the situation from the opponent's viewpoint and form an estimate of the opponent's likely expenditure, perhaps based on experience with other opponents in other cases.

Several comments on the model and its assumptions are in order. First, the assumption that the stakes are equally valued by both parties is merely a normalization and can be relaxed without loss of generality. The analysis of unequal stakes is equivalent to that of unequal costs, since, as the discussion below demonstrates, it is the ratio of stakes to costs that determines optimal expenditure for each party. ${ }^{6}$ Second, I ignore the admittedly important issue of asymmetric information and the associated strategic incentives. Still, the parties may be able to estimate opposing expenditure accurately from signals such as the number of documents filed or the seniority of the lawyer assigned to the case. Third, legal services in reality are a highly complex good, and the parties must rely on their lawyers to choose the amount of litigation inputs. The lawyers may be more or less constrained by the clients' interests, depending on the strength of professional ethical requirements and reputational concerns. I abstract here from any problems of agency incentives.

Most important, the model's focus on litigation rather than suit and settlement requires a few interpretative caveats. First, any attempt to test the model, or to use it to explain empirical regularities, will have to account for the selection bias arising from any systematic differences between cases that go to trial and cases 
that do not. Second, the model abstracts from many factors that explain why disputes do not settle. Some of these factors-such as differences in the parties' stakes or differences in their beliefs about the merits of the dispute, as long as the differences are common knowledge-can be incorporated into the analysis with modest extensions. ${ }^{7}$ Other complications will have to be deferred to later analyses.

Returning to the discussion, the model requires the plaintiff and defendant, respectively, to solve the simultaneous maximization problems:

$$
\operatorname{Max}_{X} A q(X, Y)-C X \quad ; \quad \operatorname{Max}_{Y}-A q(X, Y)-Y
$$

Two important observations may be noted immediately. First, the resulting expenditure functions are homogeneous of degree zero in stakes and marginal cost. Multiplying stakes and cost by the same factor leaves the first-order conditions and hence the optimal amount of expenditure unchanged. Therefore, any effect resulting from a change in cost will have a symmetric result with respect to stakes, and vice versa. For example, an increase in the plaintiff's cost will have the same qualitative effect as a differential change in stakes that decreases the stakes for the plaintiff while leaving the defendant's stakes unchanged. This observation enables us to simplify the notation considerably, obtaining several results by appealing to symmetry.

Second, the designation of the parties as plaintiff and defendant is arbitrary, in that one could transfer the amount $A$ from the defendant to the plaintiff before trial and the first-order conditions would be unchanged. Indeed, the structure of the problem would be identical if the parties were competing claimants for an award neither held as an entitlement ex ante.

The function $q(X, Y)$ reflects the forces underlying the decisionmaking process of the tribunal; and it is necessary to specify this process to get a description of the equilibrium. I assume that the judge chooses the winner partly on the basis of the arguments made by the parties, partly upon the exogenous merits of the case. the relevant burdens of persuasion, and partly on random factors, including political considerations and any judicial biases. Taking all of these factors into account, the judge finds for the side that appears to her to have the stronger case. While this approach has the disadvantage of not grounding judicial behavior in an explicit model of utility maximization, it allows us to focus on the expenditure decisions of the parties while utilizing a common-sense stylized view of the judicial process. Most lawyers talk and act as if this is how judges behave.

Formally, the number of arguments made by the plaintiff and defendant are denoted as scalars $P(X)$ and $D(Y)$, respectively. The parties expend legal resources to make arguments, and there are diminishing returns to research, so that $P_{X}, D_{Y}$ $>0, P_{X X}, D_{Y Y}<0$. I assume for simplicity that the number of arguments produced by a given level of research effort does not depend upon the number of arguments presented by the opponent $\left(P_{X Y}=D_{X Y}=0\right)$, though the persuasive value of those arguments will depend upon the opponent's efforts.

The exogenous merits of the case, which reflect the state of the facts, the law, and the average judicial attitudes of the legal system as a whole, are denoted as a scalar $M$, which can be either positive or negative. $M$ is measured in units of arguments; and as it increases, the position of the plaintiff improves. $M$ can be interpreted as measuring the standard of proof; it is the number of arguments the plaintiff starts out with on or against her side before either party does any research or investigation.

One could also have the level of merits help determine $P$ and $D$; it is unclear 
what the direction of the effect of this would be in any particular case. For example, if a jurisdiction were to move from a negligence system in products liability to one of strict liability, this would clearly benefit some plaintiffs. But if the same change tended to simplify the issues so that the efforts of plaintiff's counsel were no longer so critical to plaintiff's success, additional units of expenditure would have little payoff. Whichever the direction of the effect, to the extent that changes in $M$ do alter the research cost of an additional argument, such effects will parallel those of changes in the marginal $\cos t C$ and, therefore, are not here analyzed separately."

Finally, the outcome of a case is affected by a host of unpredictable factors, including variations in the background, attitudes, and biases of judges and juries, and random elements in the argument production functions $P(X)$ and $D(Y)$. These factors are summarized as a random variable $u$, which is distributed with probability density function $\mathrm{f}(u)$ and cumulative density function $\mathrm{F}(u) .{ }^{9}$ Additionally, to distinguish the effects of increased uncertainty in the litigation process, I multiply $\|$ by a positive spread factor $S$. This suggests the judicial decision rule: find for the plaintiff if and only if $P+M>D+S u$.

This rule implies that the probability of a plaintiff's verdict $q$ equals $\mathrm{F}[(P+M-D) / S]$. In the subsequent analysis, I denote the decision threshold as $T \equiv P+M-D$, and the variable $S$ is suppressed in the notation. ${ }^{10}$

Example: Let $P(X)=\alpha \log X, \mathrm{D}(Y)=\beta \log Y$, and let $\mathrm{F}(u)$ be the logistic distribution function $e^{\prime \prime} /\left(1+e^{\prime \prime}\right)$. Then it follows that:

$$
q(X, Y)=\frac{e^{M} X^{\alpha}}{e^{M} X^{\alpha}+Y^{\beta}}
$$

and for $M=0$ (even merits) and $\alpha=\beta=1, q(X, Y)$ reduces to $X /(X+Y)$.

I make the following assumptions about the density function $\mathrm{f}(u)$ :

$$
\begin{gathered}
\mathrm{f}(u)>0, \text { for all } u \in[-\infty, \infty] \\
\int u \mathrm{f}(u) \mathrm{d} u=0 \\
\mathrm{f}^{\prime}(u)>0 \quad \text { if and only if } u<\mathrm{F}^{-1}(0.5) ; \\
\mathrm{f}^{\prime}(u)=0 \quad \text { if and only if } u=\mathrm{F}^{-1}(0.5) ; \\
\mathrm{f}^{\prime}(u)<0 \text { if and only if } u>\mathrm{F}^{1}(0.5) ;
\end{gathered}
$$

Assumption (2) states that all deviations have some positive probability. Assumption (3) states that $\mathbf{f}(u)$ has a mean equal to zero. This is a normalization rather than an assumption, since any nonzero mean is contained in the merits variable $M$. Assumption (4) states that $\mathrm{f}(u)$ has a single mode and that its mode is equal to its median; intuitively, larger deviations from the median are less common than smaller deviations. ${ }^{11}$

\section{INDIVIDUAL MAXIMIZATION}

Returning to the decision problems of the litigants, the plaintiff and defendant choose $X$ and $Y$ to maximize their objective functions $U=A F(T)-C X$ and 


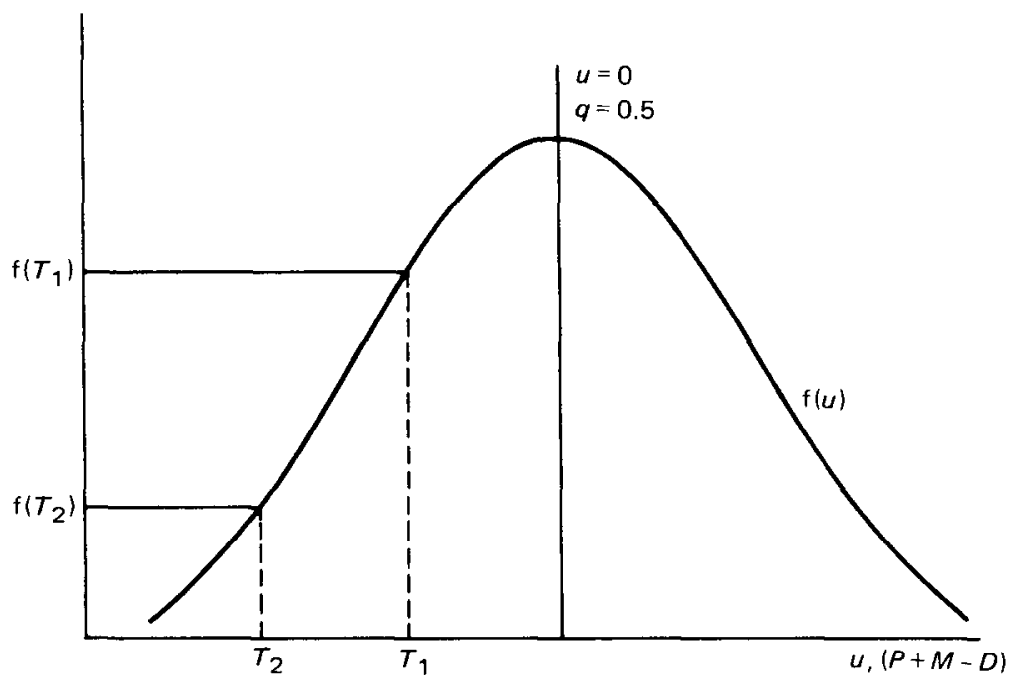

Figure 1. Density function in $u$ : movements in decision threshold

$V=-A F(T)-Y$. Differentiating $U$ and $V$ with respect to $X$ and $Y$, respectively, we obtain the first-order conditions for an optimum, which are:

$$
\begin{aligned}
& A f P_{X}-C=0 \text {, or equivalently } A f=C / P_{X} \\
& A f D_{Y}-1=0, \text { or equivalently } A f=1 / D_{Y}
\end{aligned}
$$

The interpretation of Equations $5 \mathrm{a}$ and $5 \mathrm{~b}$ is natural. The parties set the marginal expected value of an additional argument, $A f$, equal to the marginal cost of an additional argument.

It is worth observing here that the marginal value of expenditure is proportional to the probability that an additional argument will be decisive; this is just the density $\mathrm{f}(T)$. Furthermore, since density is higher nearer the median of the distribution, the marginal value of expenditure rises as the probability of liability nears 50 percent. This can be seen in Figure 1. When a party makes an additional argument, the decision threshold moves, changing the probability of liability. Moving the decision threshold in closer cases will counteract small random influences; moving the decision threshold in less close cases will counteract the influence of larger random influences. Since smaller random influences are more common than larger ones, an additional argument has a greater influence in closer cases. This is the central insight underlying the analysis to follow. ${ }^{12}$

Denote the "favorite" as the party with greater than a 50 percent chance of winning, and the "underdog" as the party with less than a 50 percent chance of winning. As the favorite makes additional arguments, the threshold moves away from the mode of the distribution, decreasing the marginal value of expenditure. Conversely, additional arguments by the underdog raise the marginal value of expenditure. 
The second-order conditions are:

$$
\begin{gathered}
\mathbf{f}^{\prime} P_{X}^{2}+f P_{X X}=q_{X X}<0 \\
-\mathbf{f}^{\prime} D_{Y}^{2}+\mathbf{f} D_{Y Y}=-q_{Y Y}<0
\end{gathered}
$$

The determinants of expenditure are implicitly defined by the maximization conditions, Equations $5 \mathrm{a}$ and $5 \mathrm{~b}$. In geometric terms, each party's optimal expenditure depends upon her opponent's expenditure as well as upon the other variables. Refer to the curve tracing out the relationship between a party's optimal expenditure and her opponent's expenditure as the party's reaction function. Assuming that Equations 6a and 6b are satisfied, each party's optimal expenditure will vary continuously with the expenditure of her opponent. ${ }^{13}$

A choice of zero expenditure is possible as a corner solution to Equation 1, though a full analysis of the possibility is, strictly speaking, outside the scope of this model. Many small grievances or long-shot cases may not be brought because of significant fixed or overhead costs. Similarly, the cases with the highest probability of liability may not be worthwhile to defend. The important decision for the litigants in such cases is not on the intensive margin of how much to spend, but on the extensive margin of whether to spend anything at all. Assuming $P_{X}$ is sufficiently large for $X$ near zero (i.e., the first unit of research is sufficiently valuable), the plaintiff will always want to spend a positive amount, however small; the analogous condition holds for the defendant. I will usually speak in the subsequent analysis as if these conditions are satisfied, so that all parties are on the intensive margin of expenditure. The reader should keep in mind, however, that changes in exogenous variables lead to changes along the extensive margin as well, as the number of cases brought responds to the net payoff from litigation.

The effects on expenditure of small changes in the explanatory variables are found by differentiating the maximization conditions: ${ }^{14}$

$$
\begin{gathered}
A\left(\mathrm{f}^{\prime} P_{X}^{2}+\mathrm{f} P_{X X}\right) \mathrm{d} X+A\left(-\mathrm{f}^{\prime} P_{X} D_{Y}\right) \mathrm{d} Y+A \mathrm{f}^{\prime} P_{X} \mathrm{~d} M \\
\quad+A\left[-P_{X}\left(\mathrm{f}+T \mathrm{f}^{\prime}\right)\right] \mathrm{d} S+\mathrm{f} P_{X} \mathrm{~d} A-\mathrm{d} C=0 \\
A\left(-\mathrm{f}^{\prime} P_{X} D_{Y}\right) \mathrm{d} X+A\left(\mathrm{f}^{\prime} D_{Y}^{2}-\mathrm{f} D_{Y Y}\right) \mathrm{d} Y+A\left(-\mathrm{f}^{\prime} D_{Y}\right) \mathrm{d} M \\
\quad+A\left[D_{Y}\left(\mathrm{f}+T \mathrm{f}^{\prime}\right)\right] \mathrm{d} S+\left(-\mathrm{f} D_{Y}\right) \mathrm{d} A=0
\end{gathered}
$$

One observation follows immediately. The oligopoly literature suggests that the signs of the slopes of the reaction functions are the critical determinants of parties' strategic behavior in Stackelberg and similar equilibria. ${ }^{15}$ Although I have argued for the Nash equilibrium as the basic solution to the litigation game, it would still be interesting to know the direction of a party's response to a marginal increase in expenditure by her opponent. Call a party's expenditure provocative if a marginal increase in her expenditure leads to an increase in her opponent's expenditure; conversely, a party's expenditure is deterring if a marginal increase in her expenditure leads to a decrease in her opponent's expenditure. One might suppose that litigation expenditure is either provocative for both parties, as lawyers often claim, or deterring for both.

Rearrangement of Equations $7 \mathrm{a}$ and $7 \mathrm{~b}$ shows that the slope of the plaintiff's reaction function is equal to $\mathrm{d} Y / \mathrm{d} X=-q_{X X} / q_{X Y}$, and that the slope of the defendant's reaction function is equal to $\mathrm{d} Y / \mathrm{d} X=-q_{X Y} / q_{Y Y}$. Since $q_{X X}<0$ and $q_{Y Y}>0$, the two slopes must be of opposite signs when they intersect. ${ }^{16}$ Note that this result does not depend upon any specific model of judicial decision, but 
holds generally for any function $q(X, Y)$, provided both parties' expenditures affect the outcome and have diminishing returns. Thus:

Proposition 1: At a Nash equilibrium in expenditure, exactly one party is provocative and exactly one party is deterring.

This suggests that outcomes other than the Nash equilibrium may be possible, since a party might act strategically to influence her opponent's expenditure level. If the scope for strategic behavior is small, the deterring party is the more likely candidate for strategic leader, since she can induce her opponent marginally to reduce expenditure by slightly increasing her own spending. To do this, she might commit in various ways to sink legal resources in advance. It is conceivable but less likely that the provocative party could respond strategically as well. Since the decision to overspend, unlike the decision to underspend, is likely to be irrevocable, it is therefore more likely to be a credible commitment. ${ }^{17}$

Under the more specific assumptions of the model, a stronger result follows. Along the plaintiff's reaction function (Equation 7a), the partial derivative of defendant's expenditure with respect to plaintiff's expenditure is:

$$
\frac{\mathrm{d} Y}{\mathrm{~d} X}=\frac{-q_{X X}}{q_{X Y}}=\frac{\mathrm{f}^{\prime} P_{X}^{2}+\mathrm{f} P_{X X}}{\mathrm{f}^{\prime} P_{X} D_{Y}}
$$

It follows from the second-order conditions that the numerator of Equation 8 is ncgative. Thus, sgn $[\mathrm{d} Y / \mathrm{d} X]=-\operatorname{sgn}\left[\mathrm{f}^{\prime}\right]$. But, recalling the key idea discussed earlier, the marginal value of expenditure rises when the case is made closer. Expenditure by the underdog makes the case closer and expenditure by the favorite makes the case less close. Therefore:

Proposition 2: In equilibrium, the expenditure of the favored party is deterring, and the expenditure of the underdog is provocative.

The precise statement of Proposition 2, though not its spirit, depends on the assumption that the mode and median of the probability density distribution are equal. More generally, if the median of the distribution is not equal to the mode, then $q$ would take a value $q^{*}$ at the mode and all results would be symmetric around $q=q^{*}$ rather than around $q=0.5 .^{18}$

\section{EQUILIBRIUM BEHAVIOR}

The Nash equilibrium of the litigation game is depicted in Figure 2. The curves $R_{X}$ and $R_{Y}$ are the reaction functions of the plaintiff and defendant, respectively. Both curves are assumed continuous and differentiable. The dotted line marked $I_{q}=0.5$ is an isoprobability curve; at all points along it the probability $q$ is equal to 0.5 . It is upward sloping because an increase in plaintiff's expenditure requires a corresponding increase in defendant's expenditure to keep the probability unchanged. Such a curve could be defined for any level of probability $q$. Denote the one corresponding to $q=0.5$ as the equiprobability curve. ${ }^{19}$

At all points above and to the left of the equiprobability curve, the defendant is the favorite; at all points below and to the right of the equiprobability curve, the plaintiff is the favorite. Note that the reaction functions change the sign of their slope as they cross the equiprobability curve, in accordance with Proposition

2. In Figure 2 the defendant is the favorite in equilibrium.

Each party's reaction function can switch the sign of its slope only once. Therefore, there are only three possibilities for the configuration of reaction functions. 


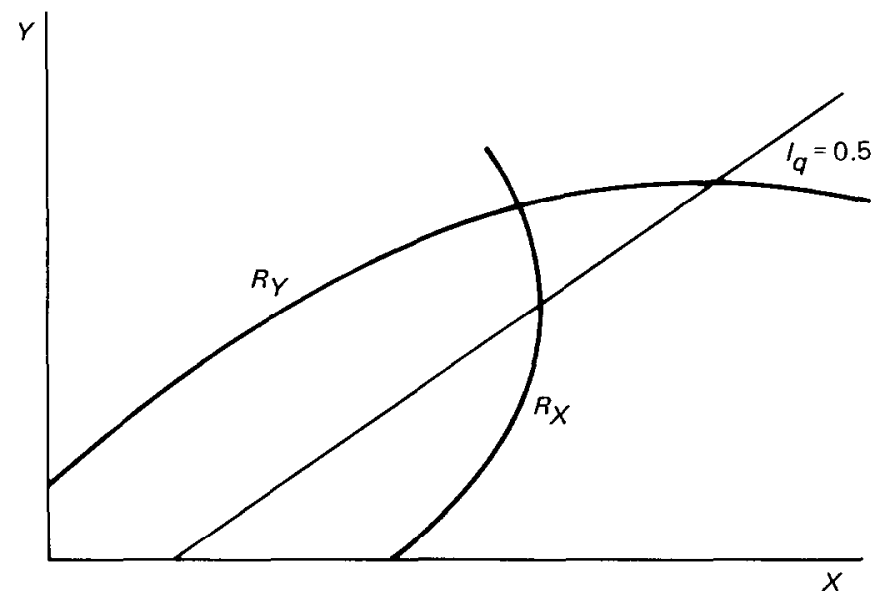

Figure 2. Nash equilibrium with the defendant favored

The first is depicted in Figure 2. The second is the symmetric case, in which the plaintiff is the favorite in equilibrium. A third possibility is that each reaction function remains on its separate side of the equiprobability curve and thus slopes upward everywhere, in which case no Nash equilibrium exists. Each party would react to any finite opposing expenditure by increasing her own. I focus attention on the cases in which there are equilibria. ${ }^{20}$

It is not generally possible to find an analytic expression that describes the conditions under which the plaintiff or defendant is favored. Which party is favored in equilibrium depends upon the values of the exogenous parameters $M, S, C$, and $A$, as well as the nature of the argument-expenditure relationships $P(X)$ and $D(Y)$. For instance, it is possible for the merits to favor the plaintiff $(M>0)$, while the plaintiff is still the underdog in equilibrium.

I now solve for reduced-form expressions for the change in the endogenous variables $X$ and $Y$. For notational convenience, denote the curvature of the respective research functions $P(X)$ and $D(Y)$ as:

$$
\pi \equiv P_{X X} / P_{X}^{2}<0 ; \quad \Delta \equiv D_{Y Y} / D_{Y}^{2}<0
$$

The variables $\pi$ and $\Delta$ measure the relative rate of diminishing returns in research. Also denote the variable $G$ as:

$$
G \equiv 1 /\left(q_{X X} q_{Y Y}-q_{X Y} q_{X Y}\right)<0
$$

Simultaneous solution of Equations $7 \mathrm{a}$ and $7 \mathrm{~b}$ then yields:

$$
\begin{aligned}
& \mathrm{d} X+G\left(q_{Y Y} q_{X M}-q_{X Y} q_{Y M}\right) \mathrm{d} M+G\left(q_{Y Y} q_{X S}-q_{X Y} q_{Y S}\right) \mathrm{d} S \\
& \quad+(G / A)\left(q_{Y Y} q_{X}-q_{X Y} q_{Y}\right) \mathrm{d} A+(G / A)\left(-q_{Y Y}\right) \mathrm{d} C=0 \\
& \mathrm{~d} Y+G\left(q_{X X} q_{Y M}-q_{X Y} q_{X M}\right) \mathrm{d} M+G\left(q_{X X} q_{Y S}-q_{X Y} q_{X S}\right) \mathrm{d} S \\
& \quad+(G / A)\left(q_{X X} q_{Y}-q_{X Y} q_{X}\right) \mathrm{d} A+(G / A)\left(q_{X Y}\right) \mathrm{d} C=0
\end{aligned}
$$


Observe that along a party's reaction function, her probability of winning decreases as her opponent spends more. Along the $R_{X}$ curve:

$$
\frac{\mathrm{d} q\left(X^{*}\right)}{\mathrm{d} Y}=q_{Y}+q_{X} \frac{\mathrm{d} X^{*}}{\mathrm{~d} Y}=\frac{-\mathrm{f}^{2} D_{Y} P_{X X}}{\mathrm{f}^{\prime} P_{X}^{2}+\mathrm{f} P_{X X}}<0
$$

The intuition behind this result is straightforward: the direct effect of opposing expenditure is to lower one's probability of winning. If the party is deterrable, the result is obvious. Conversely, if she is provocable, the indirect effect mitigates the original fall in probability. But the indirect effect provoked cannot equal or outweigh the original effect. For if it did, the marginal value of expenditure would not rise, which implies that there should have been no reaction in the first place.

This intuition can be stated more generally, and as such it constitutes a second key idea of the analysis. A change in an exogenous parameter will affect the parties' expenditures directly by changing the marginal value of expenditure and also indirectly as the parties adjust along their reaction functions to the direct change. The indirect effect of the parties' adjustment can affect the magnitude of the total effect, but not its direction. $\Lambda$ change in $M$ or $S$ has the same qualitative effect on $X$ and $Y$, taking all adjustments into account, as if all such adjustments were ignored.

This insight enables us to determine the effects on $q$ of changes in the exogenous variables. For example, virtually all economic analyses of litigation behavior assert that parties should use more units of legal resources when the stakes are higher or when the costs are lower. ${ }^{21}$ The model confirms this assertion. It follows from Equations $11 \mathrm{a}$ and $11 \mathrm{~b}$ that:

$$
\begin{aligned}
& \mathrm{d} X / \mathrm{d} C=q_{Y Y}(G / A)<0 \\
& \mathrm{~d} Y / \mathrm{d} C=-(G / A) q_{X Y}=-(G / A) \mathrm{f}^{\prime} P_{X} D_{Y}
\end{aligned}
$$

Why does this occur? Inspection of Equation 7 a reveals that the plaintiff"s reaction function shifts inward when her cost rises. Her opponent's expenditure will fall if and only if the plaintiff is the underdog. In that case the plaintiff is provocative, so the defendant responds in kind. The effect on the total amount of research done by both parties, $(X+Y)$ and the effect on the total expenditure by both parties, $(C X+Y)$, are ambiguous. 22

As for the effect on the probability of liability, if the plaintiff is the favorite and her cost rises, the defendant will increase expenditure when the plaintiff cuts hack. The plaintiff's chances of winning will then obviously fall. If conversely, the plaintiff is the underdog and her cost rises, both parties will cut back. The above discussion tells us, however, that the defendant's cutback in expenditure cannot reverse the direct effect on $q$ of the plaintiff's cutback. Therefore, when $C$ rises, as the equilibrium moves up the defendant's reaction function away from the $Y$-axis, it must be the case that $q$ falls. Confirming this algebraically:

$$
\mathrm{d} q / \mathrm{d} C=(G / A)\left(q_{Y Y} q_{X}-q_{X Y} q_{Y}\right)=-(G / A) \mathrm{f}^{2} P_{X} D_{Y Y}<0
$$

A parallel analysis follows for the defendant. In sum:

Proposition 3: An increase in a single party's marginal legal cost will lead her to spend less on research and argument. Her opponent will spend less if and only if the opponent is the favorite. In any event, an increase in a party's legal costs will decrease her probability of winning.

Because $C$ and $A$ enter the first-order condition (Equation 5a) symmetrically, a differential rise in a party's stakes in a given lawsuit is equivalent in the analysis 
to a fall in her unit costs, while a fall in stakes corresponds to a rise in costs. A corollary follows immediately by virtue of this symmetry. ${ }^{23}$

Corollary: A marginal increase in a single party's stakes in the controversy will lead her to spend more on research and arguments and will increase her probability of winning. Her opponent will spend more if and only if the opponent is the favorite.

Proposition 3 and its corollary formally confirm the argument made by Galanter (1974) and others that repeat players in litigation have a systematic advantage over one-shot litigants. Moreover, this is true under fairly general assumptions about the legal process. The analysis thus lends support to critics of the legal system who accuse it of reinforcing inequalities of wealth and bargaining power.

The corollary also lends some weak support to scholars who have stressed a tendency toward efficiency in the common law. ${ }^{24} \mathrm{~A}$ party arguing for a relatively efficient rule will, on average, have more to gain from a favorable decision than does her opponent (absent significant effects on third parties), since the efficient rule is potentially Pareto superior. Other things being equal, her stakes will therefore be higher; she will spend more, and her chances of winning will rise.

Although Proposition 3 and its corollary have long been folk wisdom in the law and economics literature, they cannot be derived from a black-box model of the judicial process; the minimal assumptions sufficient for Proposition 1 to hold indicate that relatively low-cost or high-stakes parties spend more, but do not suffice to show that their probability of victory is greater. The sticking point of such attempted proofs is in the possibility that expenditure is provocative; spending more does not guarantee a higher probability of victory if the opponent spends more as well. In this model, however, retaliatory expenditure is of secondary importance.

Next, consider the effect of a uniform change in the stakes or in both parties" costs. Virtually all economic analyses of litigation have predicted that expenditure should rise when stakes are higher or costs are lower; this model is no exception. In addition, however, changing the stakes can alter the probability of a plaintiff's victory. Observe that an increase in the value of $A$ causes both reaction functions to move outward as the marginal value of expenditure rises. From Equations 11 a and $11 \mathrm{~b}$, it follows:

$$
\begin{aligned}
& \mathrm{d} X / \mathrm{d} A=(G / A)\left(q_{X Y} q_{Y}-q_{Y Y} q_{X}\right)=(G / A) \mathrm{f}^{2} P_{X} D_{Y Y}>0 \\
& \mathrm{~d} Y / \mathrm{d} A=(G / A)\left(q_{X Y} q_{X}-q_{X X} q_{Y}\right)=(G / A) \mathrm{f}^{2} D_{Y} P_{X X}>0
\end{aligned}
$$

Both parties unambiguously increase expenditure. What is the effect on the probability of liability?

$$
\mathrm{d} q / \mathrm{d} A=q_{X}(\mathrm{~d} X / \mathrm{d} A)+q_{Y}(\mathrm{~d} Y / \mathrm{d} A)=\mathrm{f}^{3} P_{X}^{2} D_{Y}^{2}(G / A)(\Delta-\pi)
$$

The effect on $q$ thus depends on the relative size of $\pi$ and $\Delta$. The intuition behind this result is straightforward; the party with relatively weaker diminishing returns will react to the same increase with a larger increase in arguments, because she finds it cheaper to accelerate her efforts. This will influence the outcome in her favor. 
Proposition 4: An increase in the stakes will lead both parties to increase their expenditure. This will increase the probability of winning of the party with relatively weaker diminishing returns.

Corollary: An increase in the costs of both parties will lead them to reduce their expenditure. This will increase the probability of winning of the party with relatively stronger diminishing returns.

Next, what is the effect on optimal expenditure of a change in the merits? A change in the merit that benefits the favorite will shift $T$ away from the mode and make the case less close, lowering the marginal value of expenditure and moving both parties' reaction functions inward.

$$
\begin{aligned}
& \mathrm{d} X / \mathrm{d} M=-G\left(q_{Y Y} q_{X M}-q_{X Y} q_{Y M}\right)=G \mathrm{ff}^{\prime} P_{X} D_{Y X} \\
& \mathrm{~d} Y / \mathrm{d} M=-G\left(q_{X X} q_{Y M}-q_{X Y} q_{X M}\right)=G \mathrm{ff}^{\prime} D_{Y} P_{X X}
\end{aligned}
$$

As for the effect on $q$, algebraic manipulation shows it to be:

$$
\mathrm{d} q / \mathrm{d} M=-G \mathrm{f}^{2} \mathrm{II} \Delta=\mathrm{f}\left[-\mathrm{f} \pi \Delta /\left(\mathrm{f}^{\prime}(\pi-\Delta)-\mathrm{f} \pi \Delta\right)\right]>0
$$

A change in the merits in favor of a party always increases the probability of victory for that party. The total effect on the probability, however, may be different from the immediate partial effect $q_{M}=\mathrm{f}$. The total effect is larger than the partial effect if and only if the favored party has relatively stronger diminishing returns to research. To see this, suppose, for example, that plaintiff is the underdog and the defendant has stronger diminishing returns. In that case, an increase in $M$ favors the underdog and causes both parties to increase expenditure. But because the plaintiff has weaker diminishing returns, her increase in expenditure is greater and the effect is magnified. Summarizing:

Proposition 5: A change in the merits that benefits the underdog (favorite) will cause both parties to increase (decrease) expenditure. The party benefited by the change in merits will have an increased chance of winning in equilibrium.

The implication of Proposition 5 is that other things being equal, more resources will be spent in closer cases. This result is in the spirit of other findings that close cases engender more litigation. ${ }^{25}$ In contrast to previous work, however, the results do not turn on the litigation/settlement decision or on any assumptions of differential information.

Finally, the effect of an increase in the variability of the decisionmaker is somewhat surprising. An increase in $S$ is a type of mean-preserving spread; it takes weight out of the center of the probability density distribution and puts it into the tails. For many familiar probability distributions, including the normal and the logistic, there exists a cutoff point $T^{*}$ that clearly separates the center from the tails; specifically, an increase in $S$ will decrease $f(T)$ for all $T \in\left[-T^{*}, T^{*}\right]$ and will increase $\mathrm{f}(T)$ for all $T$ greater than $T^{*}$ or less than $-T^{*} .{ }^{26}$ Let us call cases "close" or "closely matched" if equilibrium $T$ is in the center of the distribution (i.e., equilibrium $q$ is sufficiently near 0.5 ), and "one-sided" if equilibrium $T$ is in the tails (equilibrium $q$ is near either 0 or 1 ). Since the marginal value of expenditure is proportional to the density $\mathrm{f}(T)$, it follows that increasing the variance of judicial uncertainty causes expenditure to fall in close cases and rise in one-sided cases. ${ }^{27}$ 
The effect in equilibrium is:

$$
\begin{aligned}
\mathrm{d} X / \mathrm{d} S & =-G\left(q_{Y Y} q_{X S}-q_{X Y} q_{Y S}\right)=-G \int P_{X} D_{Y Y}\left[\mathrm{f}+T \mathrm{f}^{\prime}\right] \\
\mathrm{d} Y / \mathrm{d} S & =-G\left(q_{X X} q_{Y S}-q_{X Y} q_{X S}\right)=-G \mathbf{f} D_{Y} P_{X X}\left[\mathrm{f}+T \mathrm{f}^{\prime}\right] \\
\mathrm{d} q / \mathrm{d} S & =q_{S}+q_{X}(\mathrm{~d} X / \mathrm{d} S)+q_{Y}(\mathrm{~d} Y / \mathrm{d} S)+ \\
& \left.=-T \mathrm{f}+G \mathrm{f}^{3} P_{X}^{2} D_{Y}^{2}(\pi-\Delta) \mathrm{f}+T \mathrm{f}^{\prime}\right)
\end{aligned}
$$

The first term is positive if and only if the plaintiff is the underdog. The sign of the second term depends on both $(\pi-\Delta)$, the relative diminishing returns, and upon $\left(f+T f^{\prime}\right)$, the effect of a spread on the marginal value of argument. The second term is positive either if (1) the defendant has stronger diminishing returns and the case is relatively one-sided, or if (2) the plaintiff has stronger diminishing returns and the case is relatively close. It is difficult to assess the empirical importance of these factors. If $\pi$ and $\Delta$ are relatively similar in magnitude, however, the sign of the first term will determine the sign of the entire expression, and increases in the variance of judicial error will increase the chances of the underdog. As a possible illustration, this may account for the common preference of criminal defendants and antitrust plaintiffs for a jury trial over a bench trial. Such parties are likely to be underdogs; it is also likely that the variance of a jury's error term exceeds that for a judge. ${ }^{28}$ T'o summarize:

Proposition 6: An increase in the variability of the decisionmaker will calse parties in relatively close cases to reduce expenditure, and will cause parties in relatively one-sided cases to increase expenditure. For litigants with sufficiently equivalent rates of diminishing returns, increased variability will increase the chances of the underdog.

Proposition 6 runs partially counter to the folk wisdom among lawyers that increased dispersion of judicial decisions will increase litigation expenditures. Rather, introduction of judicial uncertainty in a regime of clearly established legal entitlements should increase expenditure, since most cases will be relatively onesided. But in a legal regime where uncertain entitlements mean that cases are already close, an increase in uncertainty will actually reduce litigants' expenditures. ${ }^{29}$

\section{EXTENSIONS AND CONCLUSIONS}

This article developed and analyzed a model of litigation in which the parties choose the amounts they spend on legal research and argument, given that a dispute has arisen. Unlike other analyses that simply take as given the fact that resources spent on litigation tend to pay off in terms of favorable outcomes. I explicitly model the expenditure-outcome relationship.

In this model, parties spend resources on legal research to produce arguments that will help influence the court's decision in their case. The arguments are influential because they alter the likelihood that the decision will be based on a host of minor factors that in the aggregate appear to be random. The model implied, among other things, that (a) the favored party's expenditure is deterring on the margin and the disfavored party's expenditure is provocative on the margin; (b) a change in the merits or in the underlying law that make the case closer will cause both parties to increase their expenditures: (c) an increase in a party's unit 
cost of legal resources will decrease that party's chance of victory; and (d) an increase in the variability of the tribunal increases the underdog's chances of winning but has an ambiguous effect on expenditure.

One could extend the model to cover disputes over the level of damages or cases with multiple elements of liability. Since the distribution of random factors may differ among issues or for conjunctive and disjunctive liability rules, the extension may alter some of the conclusions. It would also be interesting to apply the framework to rules of civil discovery, which govern the extent to which parties must reveal their private information about the case and so affect the incentives to spend resources on litigation. Yet another application would be to the law of collateral estoppel, which allows factual and legal findings in one lawsuit to be applied without relitigation in another. While liberal use of collateral estoppel has been widely alleged to save costs and to assist litigants with limited resources, the results here suggest that it may have the opposite effect by widening the expenditure gap between repeat and one-shot litigants.

One could also use this framework to analyze rules regarding the financing of litigation. If the losing party had to pay the winner's legal fees (the English practice), at least two additional complications would arise. First, since the allocation of legal costs would turn on the outcome of the substantive issue in a lawsuit, the effective stakes would be higher, introducing interactions between the stakes effect and the deterring or provocative aspects of expenditure. Second, the effective marginal cost of expenditure would depend endogenously on the probability of liability. The latter effect could raise issues of the existence of equilibrium.

Useful insights could also be obtained by relaxing the assumption that the outcome to the litigation game is a Nash equilibrium in expenditure. For instance, one party or another may be able to commit to enough expenditure to reach a preferred point. Parties who have the option of keeping a lawyer on retainer presumably would have the advantage in this contest. If ex ante commitment is not feasible, there may be a race of expenditure, in which each party tries to commit enough resources to get to the favored outcome.

More broadly, the results here may have application to the general phenomenon of rent-seeking under uncertainty. There are many cases of strategic behavior aimed at altering the distribution of endowments or rents; examples include patent races and research and development competition, expenditures on theft and its prevention, resources spent to gain a monopoly, and political lobbying. Litigation behavior can be viewed as a special case of this category. If this analysis is any indication, one would expect expenditures on and outcomes of rent-seeking to depend on factors analogous to those described here.

Testing the predictions of the model against the empirical evidence is an obvious next step. It would be particularly worthwhile to test the core hypothesis that expenditure is higher in closer cases, though this is likely to be difficult due to the absence of an objective measure of a case's closeness. Similarly, one could test the broader hypotheses of Propositions 1 and 2 against the common assertion on the part of attorneys that all expenditure is provocative. There will be at least two major difficulties, however, in conducting such tests. First, since some of the determinants of expenditure at trial also influence the likelihood that a case will go to trial, it will be necessary to correct for the effects of selection bias in any data sample. Second, some of the important hypotheses concern relationships between endogenously determined variables, and, to make matters worse, some of those variables. such as the closeness of the case or the identity of the underdog, are not individually observed. One possible strategy would be to interpret the 
model as applying to rent-seeking expenditure generally, and to test it in situations where these difficulties with data do not arise. ${ }^{30}$

Ultimately, once the outcome of litigation is better understood, we may be able to gain a clearer appreciation of the choice between litigation and settlement, of the plaintiff's decision to bring suit in the first place and of the defendant's decision to defend, and indeed of the choice of initial behavior that may have led to the dispute. It is hoped that the present article will contribute to such an understanding.

\section{NOTES}

1. For example, in the federal district courts, the number of civil filings rose by 77 percent from 1970 to 1979 and by 161 percent from 1960 to 1979. The number of federal appeals filed has risen from 3,899 in 1960 to 10.248 in 1969 to 20,219 in 1979. In terms of outlays of resources, the total budget for the federal judicial branch rose from $\$ 48$ million in 1960 to $\$ 503$ million in 1979. Bator et al. (1981), pp. 7, 10,13 (compiled from statistics published in 1979 Ad. Off. Rep.).

2. See, e.g. . Landes (1971), Posner (1973). Gould (1973), Shavell (1982a, 1982b), Menell (1983), P'ng (1983), Bebchuk (1984), and Reinganum and Wilde (1986).

3. The main exceptions are Landes (1971), Posner (1977: 445) and Braeutigam, Owen, and Panzar (1984). The paper by Braeutigam and co-authors is closest in approach to this one; however, it focuses on the consequences of fee shifting rules and does not model the judicial decision process. Goodman (1978) suggests a model similar to this one but is interested more in the evolution of legal precedent than in the amount of expendilure.

4. Even when the parties expect the case to settle, they might (and often do) spend legal resources in hopes of indirectly influencing the settlement amount by affecting the expected trial outcome. The model below may accordingly help shed some nonrigorous light on presettlement expenditures.

5. The analysis could also accommodate increasing marginal costs without loss of generality.

6. The assumption that the stakes are not an issue in the proceedings is a stronger one. The analysis of disputed stakes is similar but not identical to disputed liability. The relation between the two with respect to the issue of selection of cases for trial and settlement is discussed by Priest and Klein (1984), Wittman (1985), and Priest (1985).

7. See, e.g., Rubinfeld and Perloff (1988), who combine a settlement model with a model of endogenous expenditure at trial. Some limited aspects of asymmetric information are consistent with this model's framework. For example, Cooter, Marks, and Mnookin (1982) explain failure of bargaining using a model with asymmetric information about the parties' degree of stubbornness, but no asymmetric information about the determinants of the outcome of trial.

8. If, as one might expect, a party's cost of producing arguments is lower when the merits of the case are relatively in her favor, her expenditure levels will vary accordingly. As Rubinfeld and Sappington (1987) have argued in the context of a model focusing on expenditure decisions in criminal cases (or, more generally, in cases where only one side chooses expenditure), a sophisticated but imperfectly informed decisionmaker might use either expenditure levels or the observed decision threshold $T$ as a signal of the litigants' private information regarding the merits.

9. Because of the linear form of the decision rule, uncertainty arising from the outcome of research can be incorporated in the variable $u$.

10. More precisely, all functions of $S$ are evaluated at $S=1$ without loss of generality.

11. Assumption (4) is implied by but is weaker than the assumption of a symmetric unimodal distribution. The assumption that the mode of $\mathrm{f}(u)$ equals the median is not essential to the spirit of the results below although it is needed for their precise form; the assumption that $f(u)$ is unimodal is essential.

12. Because the probability density function is unimodal with its mode equal to its median, $\mathrm{f}^{\prime}$ is positive if and only if $T<0$, i.e., if and only if $q<0.5$. 
13. A caveat is in order regarding the existence of a unique maximum; consider the plaintiff's second-order condition (Equation 6a). The first term measures diminishing or increasing returns to argument and can be of either sign depending upon whether plaintiff is the favorite or underdog. The second term reflects diminishing returns to research and is negative. If increasing returns to argument outweigh decreasing returns to research, an underdog plaintiff might face increasing returns over some ranges of expenditure. It can be shown that sufficiently large $X$ will turn $q_{X X}$ negative, implying a finite solution to the plaintiff's optimization problem. Unless there are sufficient diminishing returns to legal expenditure, however, there may be multiple local maxima, raising the possibility of a discontinuous reaction function, with potential problems for existence and uniqueness of equilibrium. In the text, I assume the reaction functions are continuous. For a derivation of the necessary and sufficient conditions for the reaction functions to be continuous; see Katz (1986), ch. 1.

14. The analysis to follow is made explicit only for the plaintiff; it is assumed that the reader could easily construct the parallel analysis for the defendant.

15. See, e.g., Fudenberg and Tirole (1984) and Bulow, Geanakoplos, and Klemperer (1985).

16. Barring, of course, the degenerate case when $q_{X Y}=0$.

17. If the parties can commit to large deviations from the Nash equilibrium, for example, by hiring a lawyer on retainer for a substantial period of time, the comparison in the text is no longer valid. A party who is provocative for small deviations from equilibrium may be deterring for larger deviations.

18. It can also be shown that if there are discontinuities in one party's reaction function, then at any discontinuity: (a) a marginal change in the merits that benefits that party will lead to a discrete increase in her expenditure; (b) a marginal increase in her stakes will lead to a discrete increase in her expenditure; (c) a marginal increase in her unit cost will lead to a discrete decrease in her expenditure; (d) a marginal increase in her opponent's expenditure will lead to a discrete decrease in her own expenditure; and (e) a marginal increase in the variance of error has an ambiguous effect on such party's expenditure. Proofs are available from the author.

19. As drawn, the equiprobability curve crosses the $X$-axis, but this need not be the case.

20. The comparative statics would be uninteresting in the third case; despite changes in the exogenous variables, both parties would still attempt to spend infinite amounts on the lawsuit.

21. See, e.g., Landes (1971), Posner (1973), Galanter (1974), Braeutigam, Panzar, and Owen (1984), and Bebchuk (1984).

22. The effect on total research when $C$ rises is ambiguous because for a deterring plaintiff, $Y$ will rise when $X$ falls. The relative magnitude of the changes in expenditure cannot be determined from the model. The effect on total expenditure is ambiguous for the same reason and also because the effect on plaintiff's expenditure $C X$ depends on the elasticity of demand for lawyers' time.

23. A rigorous derivation of the corollary would require us to drop the assumption that the stakes are equal for both sides, with an associated loss in economy of notation. Instead, I rely here on the informal argument from symmetry; a rigorous proof is straightforward and left to the reader.

24. See, e.g., Rubin (1977), Priest (1977), Posner (1977), and Goodman (1978). As the general discussion of the text indicates, the extent of the tendency toward efficiency depends upon the strength and statistical correlation of the various influences on the parties' stakes. Additionally, as Cooter and Kornhauser (1980) point out, inefficient rules will never be entirely eliminated from the common law as long as there is a finite probability of an inefficient decision in any given case.

25. For example, Priest and Klein (1984), in a model using the assumption that the parties have different information about the merits, argue that settlement is less likely in close cases.

26. One can verify that $\mathrm{df} / \mathrm{d} S<0$ if and only if $\mathrm{f}+T \mathrm{f}^{\prime}>0$, which is the case for the normal distribution if and only if $T \epsilon[-\sigma, \sigma]$.

27. It is not the case for every probability distribution that there exists some cutoff point $T^{*}$ such that an increase in $S$ increases $f(T)$ if and only if $|T|<T^{*}$. All implications that follow in the text from increasing $S$, however, hold for any mean-preserving spread 
on $f(u)$ that preserves the properties (2) through (4). As the continuous variable $S$ is only employed for convenience in exposition, I assume the existence of the cutoff point $T^{*}$.

28. Of course, there are other reasons for such a preference. One is that different triers of fact might have different views of the merits, so that $M$ might differ between judge and jury. Another reason, beyond the scope of this model, is that a jury trial involves greater delay and expense and therefore may improve the bargaining position of the underdog in settlement negotiations.

29. In situations where the law is well settled either before or after the change, changes on the extensive margin in the number of lawsuits may dominate changes in the amount of expenditure per lawsuit. It may be that this last possibility underlies the folk wisdom about the effect of uncertainty.

30. One application would be expenditure in election campaigns, where selection bias is unimportant (most elections for major office are contested) and there is an objective measure of closeness. Thanks to Charlie Brown for this suggestion.

\section{REFERENCES}

Bator, P., P. Mishkin, D. Shapiro, and H. Wechsler, eds. (1981). Hart and Wechsler's The Federal Courts and the Federal System, Supplement. Mineola, N.Y.: The Foundation Press.

Bebchuk, L. (1984). "Litigation and Settlement Under Imperfect Information." Rand Journal of Economics, 15, 404-15.

Braeutigam, R., B. Owen, and J. Panzar (1984). "An Economic Analysis of Alternative Fee Shifting Systems." Law' and Contemporary Problems, 47, 173-85.

Bulow, J., J. Geanakoplos, and P. Klemperer (1985). "Multimarket Oligopoly: Strategic Substitutes and Complements." Journal of Political Economy, 93, 488-511.

Cooter, R.. and L. Kornhauser (1980). "Can Litigation Improve the Law without the Help of Judges?" Journal of Legal Studies, 9, 139-63.

_. S. Marks, and R. Mnookin (1982). "Bargaining in the Shadow of the Law: A Testable Model of Strategic Behavior." Journal of Legal Studies, 11, 225-51.

Fudenberg, D., and J. Tirole (1984). "The Fat-Cat Effect, the Puppy-Dog Ploy, and the Lean and Hungry Look." American Economic Review, 74, 361-66.

Galanter, M. (1974). "Why the 'Haves' Come Out Ahead: Speculations on the Limits of Legal Change." Law and Society Review, 9, 95-160.

Goodman, J. (1978). "An Economic Theory of the Evolution of the Common Law." Journal of Legal Studies, 7, 393-406.

Gould, J. (1973). "The Economies of Legal Conflicts." Journal of Legal Studies, 2, 279-300.

Katz, A. (1986). "Essays in the Economics of Litigation." Ph.D. diss., Harvard University, Cambridge.

Landes, W. (1971). "An Economic Analysis of the Courts." Journal of Law and Economics, 11, 61-107.

and R. Posner (1976). "Legal Precedent: A Theoretical and Empirical Analysis." Journal of Law and Economics, 19, 249-307.

Menell, P. (1983). "A Note on Private versus Social Incentives to Bring Suit in a Costly Legal System." Journal of Legal Studies, 12, 41-52.

P'ng, I. P. L. (1983). "Strategic Behavior in Suit, Settlement, and Trial." Bell Journal of Economics, 14, 539-50.

Posner, R. (1973). "An Economic Approach to Legal Procedure and Judicial Administration." Journal of Legal Studies, 2, 399-458.

- (1977). Economic Analysis of Law, 2nd ed. Boston: Little, Brown and Company.

Priest, G. (1977). "The Common Law Process and the Selection of Efficient Rules." Journal of Legal Studies, 6, 65-82.

(1985). "Reexamining the Selection Hypothesis: Learning from Wittman's Mistakes." Journal of Legal Studies, 14, 215-43.

, and B. Klein (1984). "The Selection of Disputes for Litigation," Journal of Legal Studies, 13, 1-55. 
Reinganum, J., and L. Wilde (1986). "Settlement, Litigation, and the Allocation of Litigation Costs." Rand Journal of Economics, 17, 557-66.

Rubin. P. (1977). "Why is the Common Law Efficient?" Journal of Legal Studies, 6, $51-63$.

Rubinfeld, D., and J. Perloff (1988). "Settlements in Private Antitrust Litigation, " in Private Antitrust Litigation: New Evidence, New Learning, ed. L. White, 149-84. Cambridge, Mass.: MIT Press.

, and D. Sappington (1987). "Efficient Awards and Standards of Proof in Judicial Proceedings." Rand Journal of Economics, 18, 308-15.

Shavell, S. (1982a). "Suit, Settlement and Trial: A Theoretical Analysis under Alternative Methods for the Allocation of Legal Costs." Journal of Legal Studies, 11, 55-81.

- (1982b). "The Social versus the Private Incentive to Bring Suit in a Costly Legal System." Journal of Legal Studies, 11, 333-39.

Wittman, D. (1985). "Is the Selection of Cases for Trial Biased"” Journal of Legal Studies, $14,185-214$. 